\title{
WIDE RANGE MODULATION INDEXES FEATURING CARRIER-BASED PWM STEPPED WAVEFORM FOR HALF-BRIDGE MODULAR MULTILEVEL CONVERTERS
}

\author{
MAJdeE TOHTAYONG ${ }^{1 *}$, SHEROZ KHAN ${ }^{2}$, MASHKURI YAACOB ${ }^{2}$, \\ Siti HaJAR YuSOFF ${ }^{2}$, NUR ShahIda Midi ${ }^{2}$ AND MUSSE MUHAMUd AHMEd ${ }^{3}$ \\ ${ }^{1}$ Department of Electrical Engineering, Faculty of Engineering, \\ Princess of Naradhiwas University, \\ 99, Khokkhian, Muang, Narathiwat 96000, Thailand. \\ ${ }^{2}$ Department of Electrical and Computer Engineering, Kulliyah of Engineering, \\ International Islamic University Malaysia, \\ PO Box 10, 50728 Kuala Lumpur, Malaysia. \\ ${ }^{3}$ Department of Electrical and Electronic Engineering, Faculty of Engineering, \\ Universiti Malaysia Sarawak, \\ Kota Samarahan, 94300 Sarawak, Malaysia.
}

*Corresponding author: powerelectronics911@hotmail.com

(Received: 12 ${ }^{\text {th }}$ Dec 2016; Accepted: $5^{\text {th }}$ June 2018; Published on-line: $1^{\text {st }}$ Dec 2018)

https://doi.org/10.31436/iiumej.v19.i2.788

\begin{abstract}
This paper presents simulation results of the influence of wide range modulation index values $\left(m_{a}\right)$ in carrier-based PWM strategy for application in generating the stepped waveform. The waveform is tested for application in single-phase half-bridge modular multilevel converters (MMCs) topology. The results presented in this paper include a variation of the fundamental component $(50 \mathrm{~Hz})$ in the voltage output. It also studies total harmonic distortion of the output voltage (THDv) and the output current (THDi) when the modulation index is changed over the linear-modulation region, $0<m_{a}$ $<1$. It also explores the effect of a modulation index greater than 1. Moreover, different output voltage shapes, as a consequence of varied $m_{a}$ on MMCs, are also illustrated for showing the effect of varying the value of $m_{a}$ on sub-module of MMCs.

ABSTRAK: Penulisan ini berkenan simulasi pengaruh pelbagai nilai indeks modulasi $m_{a}$ ) dalam strategi PWM berasaskan aplikasi dalam menghasilkan bentuk gelombang yang bertingkat. Bentuk gelombang ini diuji untuk aplikasi dalam topologi MMCs. Penilaian dan hasil dari artikle ini termasuk variasi komponen asas $(50 \mathrm{~Hz})$ dalam voltan keluar. Ia juga meneliti jumlah penyelarasan harmonik voltan keluar (THDv) dan arus keluaran (THDi) apabila indeks modulasi ditukar dalam rantau modulasi linear, $0<m_{a}<1$. Ia juga meneroka kesan indeks modulasi lebih daripada 1. Selain itu, bentuk voltan keluar yang berbeza sebagai akibat dari pelbagai $m_{a}$ pada MMCs juga digambarkan untuk menunjukkan kesan berbeza-beza nilai $m_{a}$ pada sub-modul MMCs.
\end{abstract}

KEYWORDS: PWM; converter; stepped waveform; MMC; THD 


\section{INTRODUCTION}

Power converters are generally used in renewable electrical energy sources' applications of the photovoltaic source or micro-hydropower [1-4]. The circuit is simple and low cost, but it needs a connection in series (or parallel) of a large number of photovoltaic panels to meet high voltage load (or grid system) demands [5]. In the case of solar, unusual environmental condition factors such as shadows from clouds, trees, buildings, dust, moisture, the temperature will cause voltage instability. On the contrary, DC-to-DC converters are proven helpful in maintaining voltage stability. Hence, DCto-DC converters are beneficial in the case that the voltage between the primary sources of photovoltaic panels and DC-link (or the DC load) remain unstable. Such inverters need be with maximum power point tracking (MPPT) features [6,7] for optimizing the amount of electrical energy harvested from the photovoltaic array to DC-link (Common Coupling Point of Micro-Grid) or the DC load [8].

On the other hand, conversion from available DC-to-AC makes an important step for grid-connectivity in distributed generation (DG) [9]. Current areas of research interest include strategic planning of electricity consumption for forecasting futuristic supply demands or suggesting areas or regions of high demand for electric supply investment. In DC-to-AC conversion, control of the modular structure of panels and devices makes the core part. This is to generate smooth output waveforms through operation of switches employed in DC-to-AC converters. However, no matter how smooth the switches operate, there remain associated harmonics as a result of level transitions. In general, each type of DC-to-AC converter topology has a unique pattern of switching operation related to the converter and its topologies such as diode-clamped inverter topology, flying capacitor inverter topology, and modular multilevel inverter topology [10,11]. Furthermore, various novel structures of MMCs are proposed to overcome this challenge, such as reducing the MMCs components or the number of power switches [12,13].

The output voltage demand of AC-load can be adjusted by DC-to-DC converters on each module of the MMCs, but in this work, we will report on varying the modulation index in carrier-based PWM strategy on MMCs to produce an output closer to the fundamental component. THD of the output voltage and output current show significant change due to modulation index variation. The carrier-based PWM strategy is flexible and easier in adjusting its value of modulation index such that the switching signals are to generate the desirable value of modulation index over a wider range without complex calculation methods such as SHEPWM strategy [14]. The modulation index is varied by the MMCs simulation in order to find the lowest value of THD and the changing pattern of the fundamental component.

The structure and switching pattern of half-bridge modular multilevel converters are given in Section 2. It shows a single sub-module operation, and also an example of MMCs module rearrangement as a single-phase 7-level half-bridge MMC. The effect of modulation index values on the carrier-based PWM strategy is introduced in Section 3. Section 4 shows the simulation result of a single-phase half-bridge MMC using six sub-module converters for releasing the maximum 7-level stepped waveform. Wherewithal, the output terminal of the MMC is connected to an AC load consisting of a single-phase induction motor. The conclusive output of this work is presented in Conclusions as Section 5 in the end. 


\section{HALF-BRIDGE MODULAR MULTILEVEL CONVERTER}

Half-bridge modular multilevel converters (half-bridge MMCs) are developed with features such as new configurations, modeling, control schemes, and modulation strategies for applications in medium or high voltage systems [15]. Other features of MMCs in focus include topology, easily implementable modular structures, highly responsive speed, harmonics mitigation, increased output power or loss reduction as a result of the improved switching frequency. For an instant, low frequency on switching in MMCs is needed to reduce switching losses and likewise enhance the overall energy efficiency of the power converter [16]. MCCs are being employed in HVDC transmission systems, in medium voltage drives (MVDs), in power quality systems, and in the distributed battery energy storage system (BESS).

MMCs are one of the famous inverter topologies used in renewable energy applications due to the fact that they can connect to several separate DC sources. The cascaded half-bridge module converters and the cascaded full-bridge module converters are two common types of MMC topology.

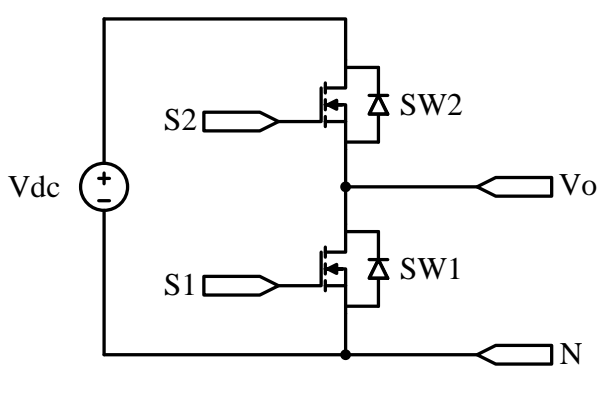

(a)

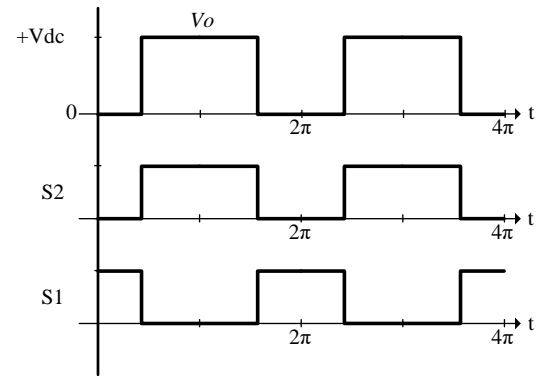

(b)

Fig. 1: (a) A module of the half-bridge converter and (b) its operation waveforms.

A half-bridge converter (HBC) is what can be used for producing complicated modular structures of inverter topologies. HBC includes two series switches and a DC source, whereas $V a$ and $N$ are connected to the load at the output terminals and its operation waveform is as shown in Fig. 1. Here, the circuit can generate two voltage levels of the DC source, $+V d c$, and zero volts. In principle, switch SW1 is turned ON and switch SW2 is turned OFF to obtain $+V d c$. On the other hand, switch SW1 is turned OFF and switch SW2 is turned ON to obtain zero volts. However, the output of a half-bridge converter, though alternating, is far from being AC voltage. Therefore, a pair of cascaded half-bridge modules is connected to generate AC output voltage in association with a lowpass filter. In addition, for grid-connected applications, the filter design is regularly a challenge to meet the grid and distribution codes [17].

The output voltage level can be increased by configuring a number of HB-MMCs appropriately. An $m$-level inverter can be connected by $m-1$ MCCs; for example, to obtain a seven-level output voltage, six modules are needed.

Figure 2(a) illustrates A single-phase half-bridge MMC for generating seven levels of output voltage. The circuit includes six modules with separated DC sources for each module. With this topology, there are three upper side modules for releasing positive output voltage at $V a$, and three lower side modules for releasing negative output voltage at $V b$. However, both output voltage $V a$ and $V b$ share the common neutral point of $N$. In addition, every single module of a single-phase half-bridge module converter generates 
different waveforms compared to other modules. Moreover, each upper and lower side module is working in a complementary fashion for producing a half period cycle of the output. For instance, SWa1, SWa2, SWa3, SWa4, SWa5, and SWa6 are operated for generating the output waveform on the first half period. The switches $S W b 1, S W b 2, S W b 3$, SWb4, SWb5, and SWb6 are operated for generating the output waveform on the second half period. Its operation waveform is illustrated in Fig. 2(b).

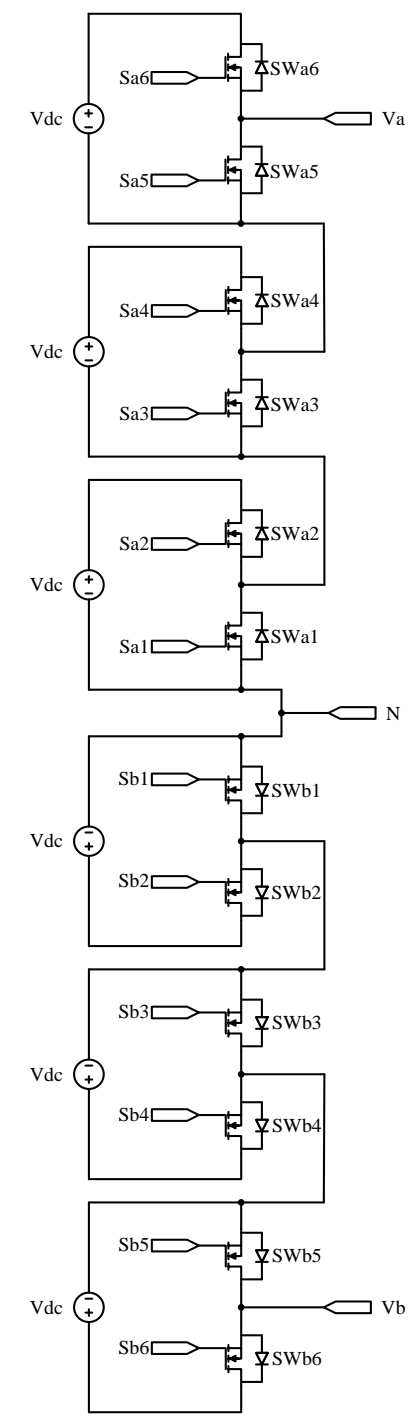

(a)

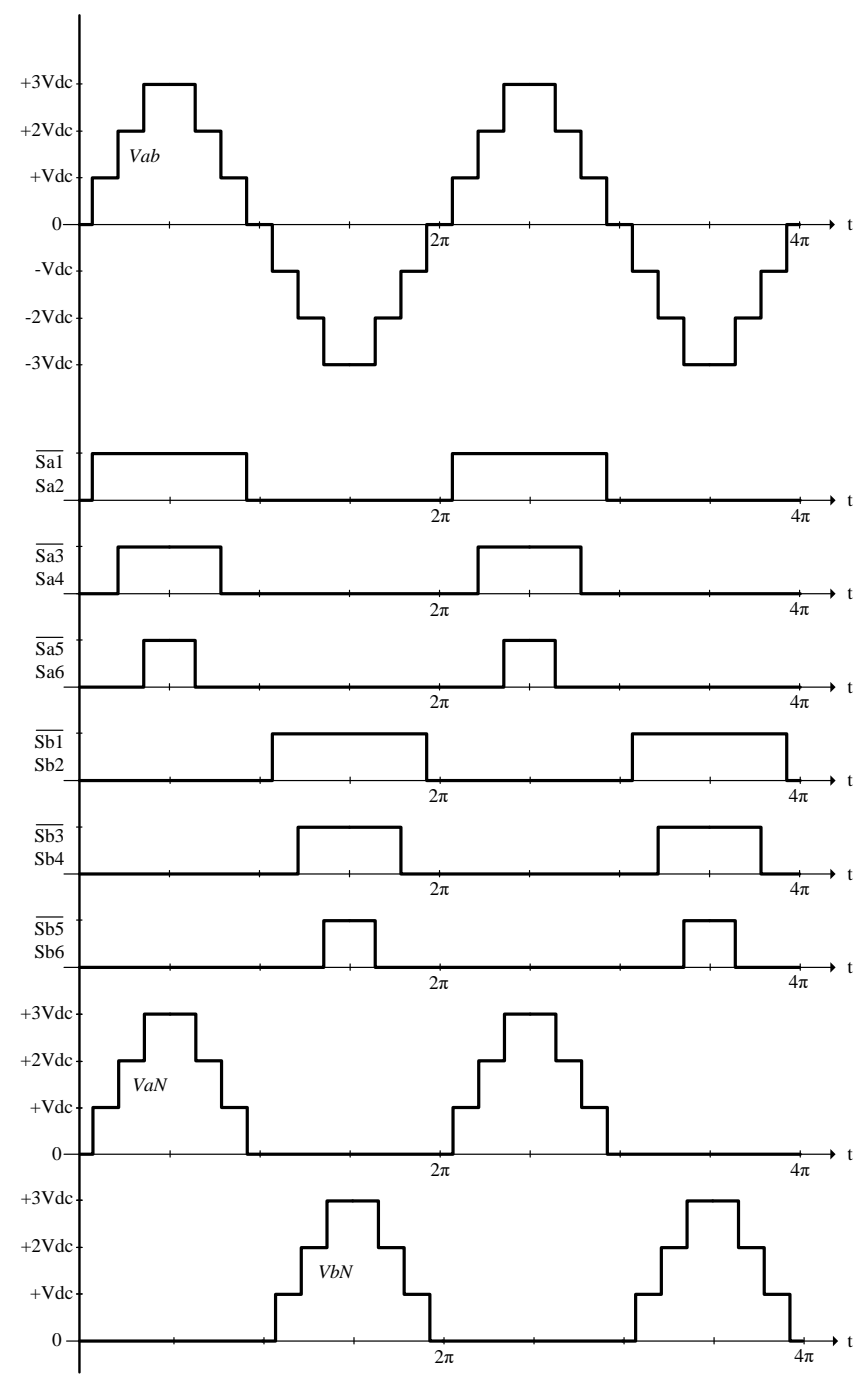

(b)

Fig. 2: (a) A single-phase 7-level half-bridge MMCs and (b) its operation waveforms.

\section{CARRIER-BASED PWM STEPPED WAVEFORM}

Numerous PWM techniques are proposed for controlling MMCs [18], producing staircase output voltage very closely approximating a sine waveform with minimized total harmonics distortion (THD). One of many PWM techniques for modular multilevel converter operation is known as carrier-based PWM strategy.

Carrier-Based PWM technique for MMC topology is the most popular and easy to implement in generating PWM signals for MMC topologies. Here, a simple sinusoidal reference waveform is compared with multi-triangular carrier signals to produce PWM signals. 


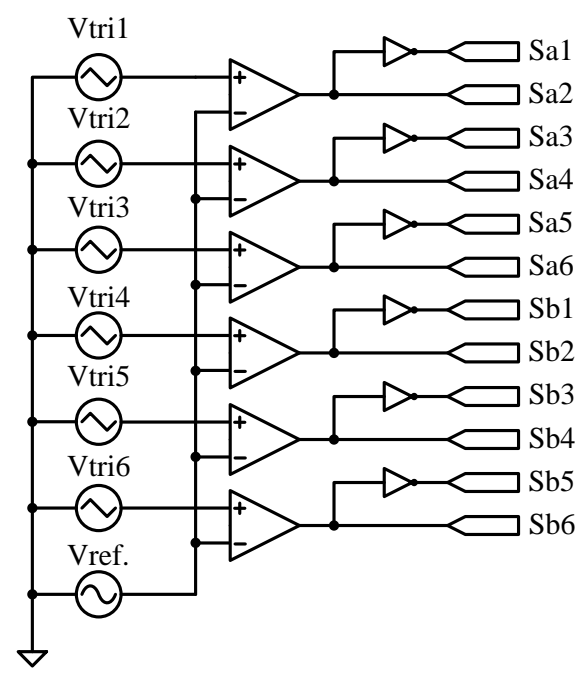

Fig. 3: An analogue circuit for carrier-based PWM simulation.

Carrier-based PWM strategy using an analog circuit is as shown in Fig. 3 above. It consists of six sub-modules of HBC for producing the 7 levels of the stepped output waveform. Furthermore, the simple sinusoidal reference waveform has amplitude, $A_{m}$, and frequency, $f_{m}$, and it is placed in the middle of the carrier signal group and a number of triangular carrier signals are equal to $m-1$, where $m$ is the number of output levels, with the same amplitude, $A_{C}$, and also the same frequency, $f_{c}$. The parameters of amplitude modulation index, $m_{a}$, and the frequency modulation, $m_{f}$, are defined by Eq. (1) and Eq. (2).

$$
\begin{aligned}
& m_{a}=\frac{A_{m}}{(m-1) \cdot A_{c}} \\
& m_{f}=\frac{f_{c}}{f_{m}}
\end{aligned}
$$

\section{SIMULATION AND DISCUSSION}

The simulation of MMCs uses the analog circuit, as shown in Fig. 3, to generate signals by carrier-based PWM technique and MMCs, as shown in Fig. 2(a), as a power circuit with an AC load which is an equivalent circuit of a single-phase induction motor with $R s=34 \Omega$ Ohm, $R r=15.2 \Omega, L l=300 \mathrm{mH}$ and $L M=1.06 \mathrm{H}$, as shown in Fig. 4. In addition, the modulation index, $m_{a}$, is varied over a wide range of 0 to 4 at frequency modulation, $m_{f}$, of 50 .

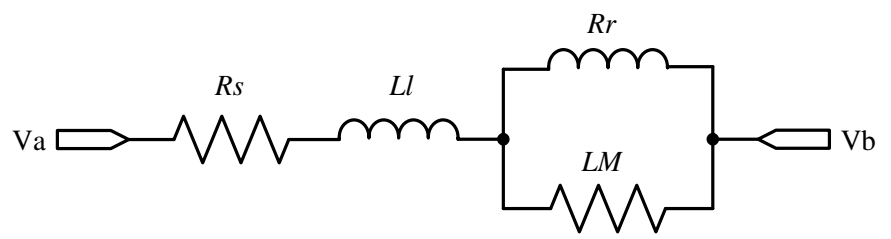

Fig. 4: The equivalent circuit of a single-phase induction motor as a load. 


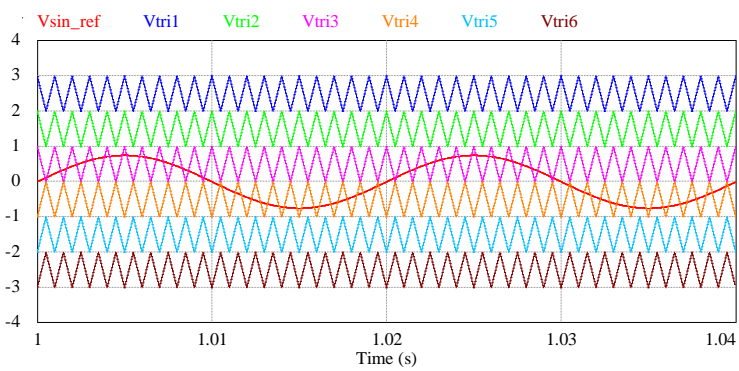

(a)

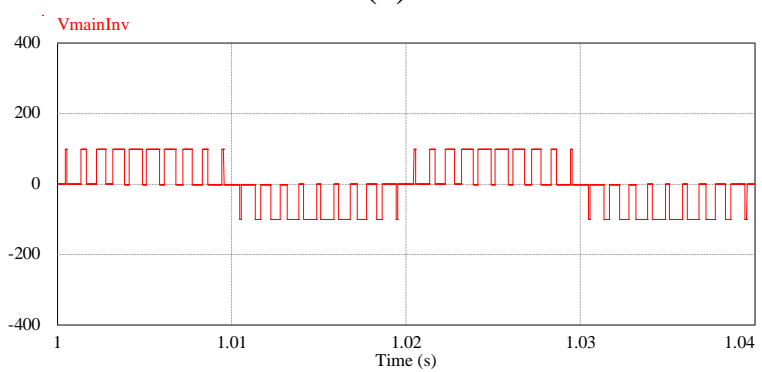

(b)

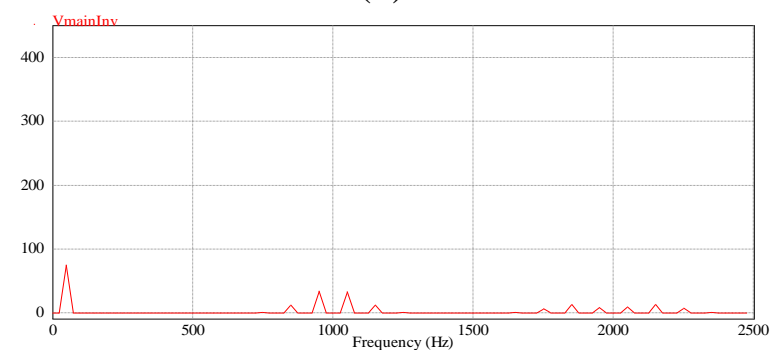

(c)

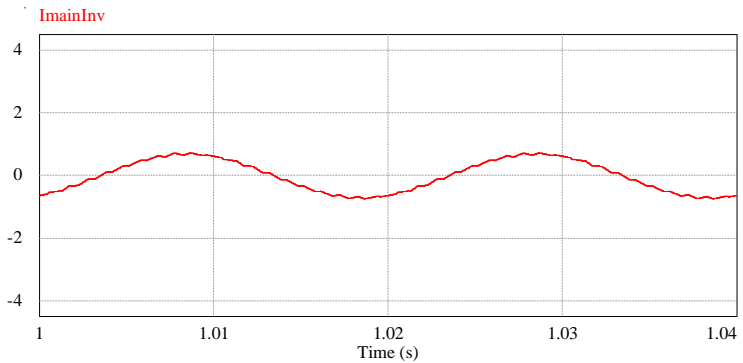

(d)

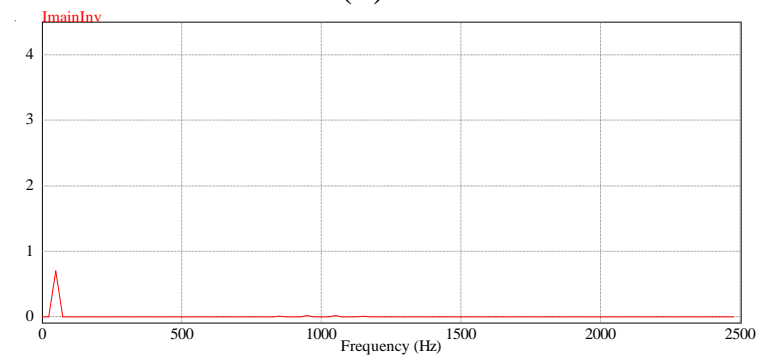

(e)

Fig. 5: (a) Multicarrier-based PWM signals at $m_{a}=0.25$, (b) the output voltage

waveform, (c) voltage harmonic spectrum, the output current waveform, and (e) current harmonic spectrum.

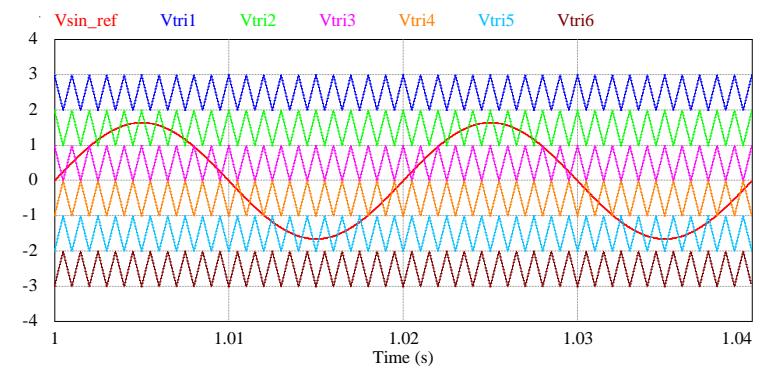

(a)

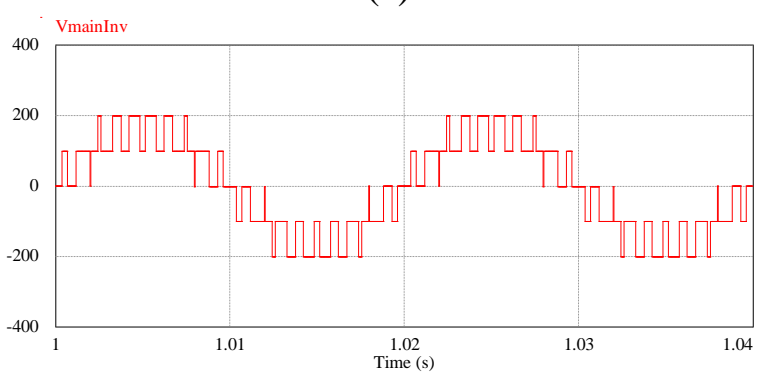

(b)

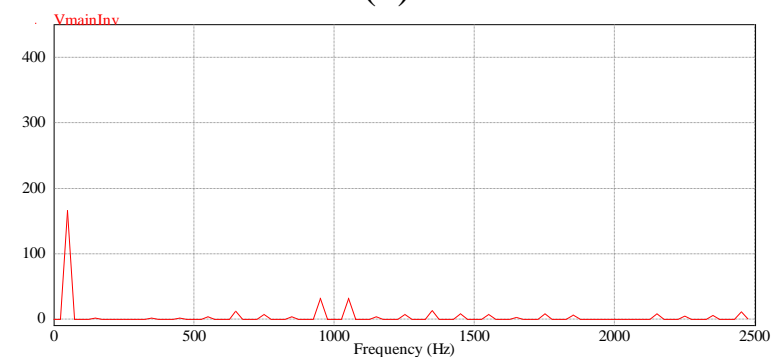

(c)

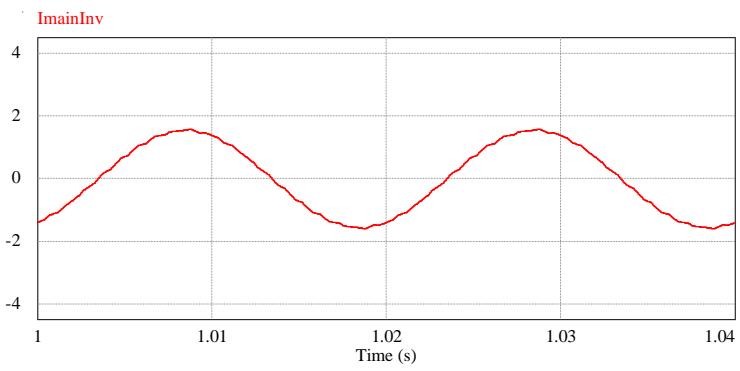

(d)

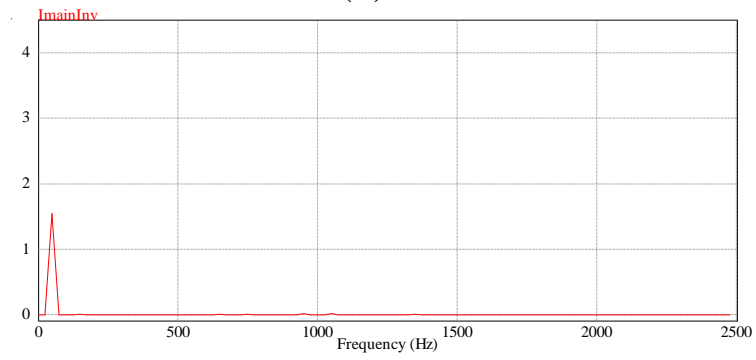

(e)

Fig. 6: (a) Multicarrier-based PWM signals at $m_{a}=0.55$, (b) the output voltage waveform, (c) voltage harmonic spectrum, the output current waveform, and (e) current harmonic spectrum. 


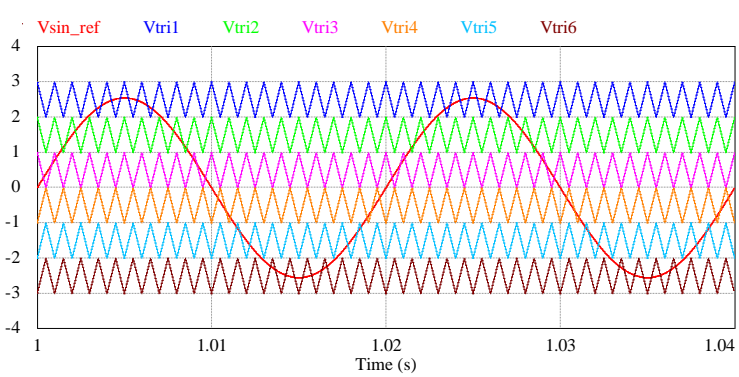

(a)

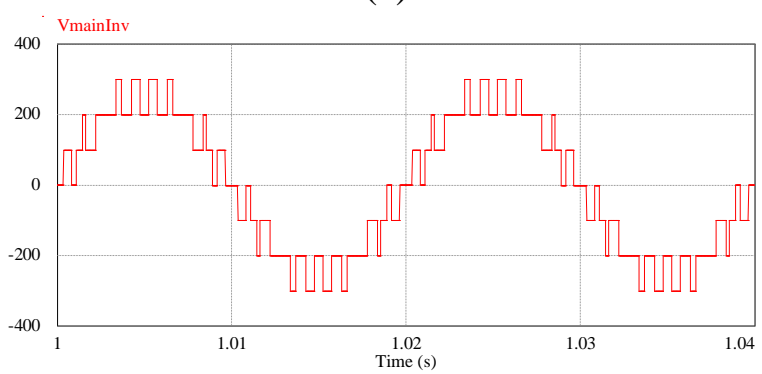

(b)

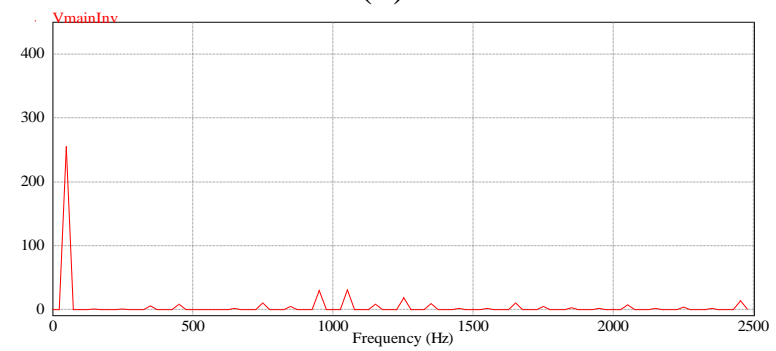

(c)

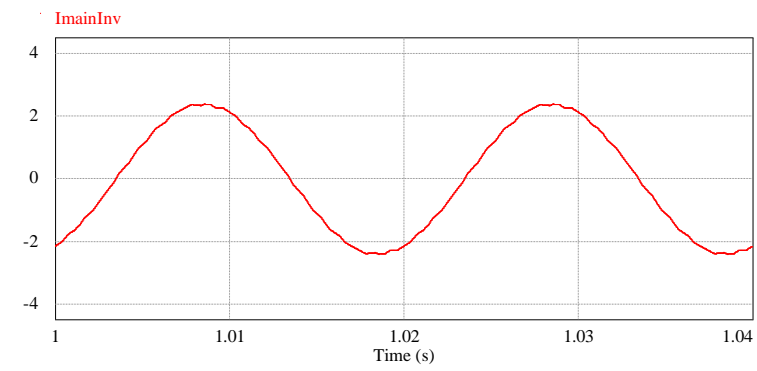

(d)

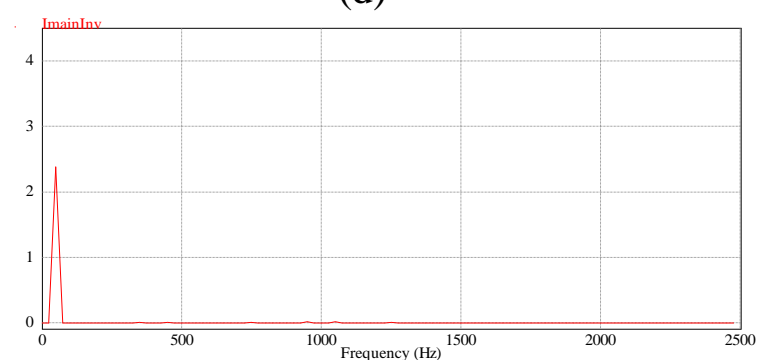

(e)

Fig. 7: (a) Multicarrier-based PWM signals at $m_{a}=0.85$, (b) the output voltage waveform, (c) voltage harmonic spectrum, the output current waveform, and (e) current harmonic spectrum.

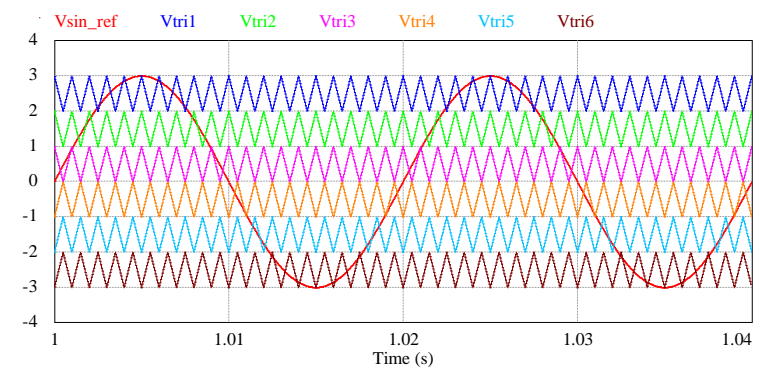

(a)

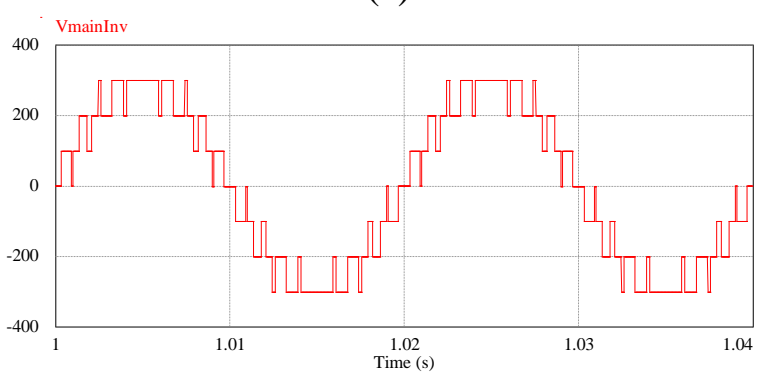

(b)

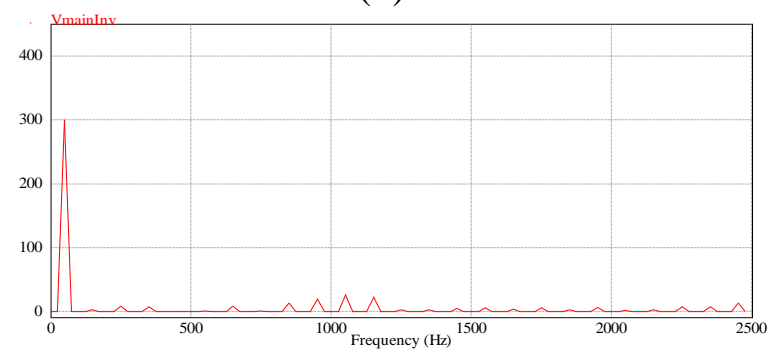

(c)

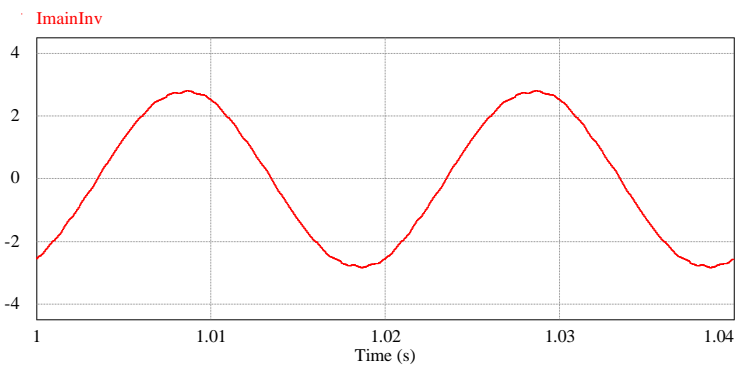

(d)

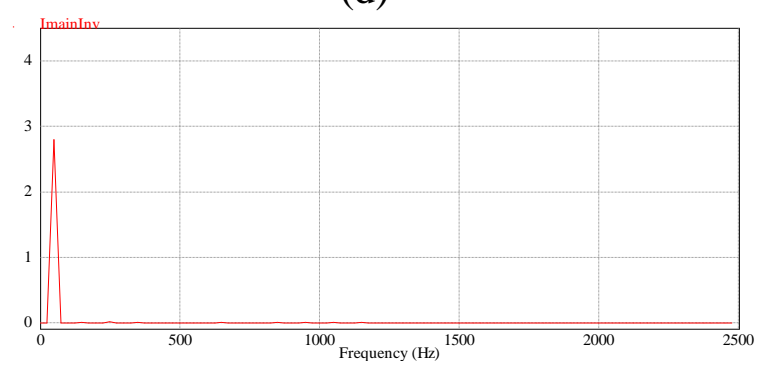

(e)

Fig. 8: (a) Multicarrier-based PWM signals at $m_{a}=1.00$, (b) the output voltage waveform, (c) voltage harmonic spectrum, the output current waveform, and (e) current harmonic spectrum. 


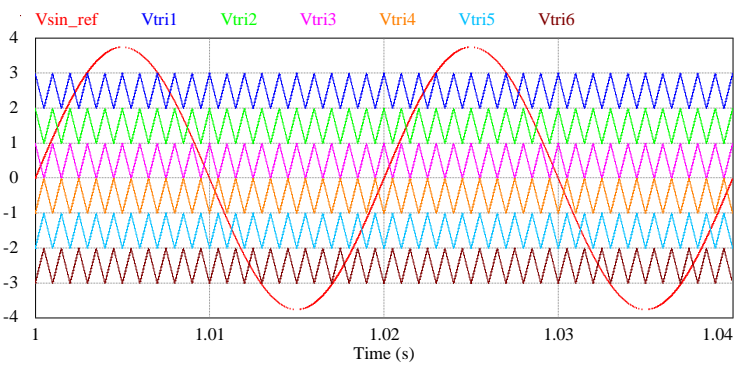

(a)

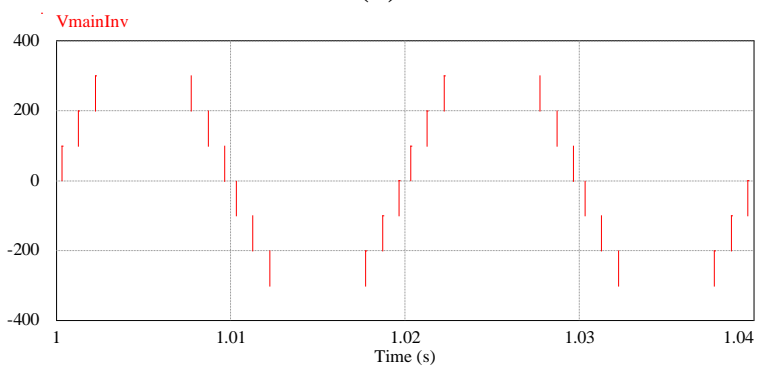

(b)

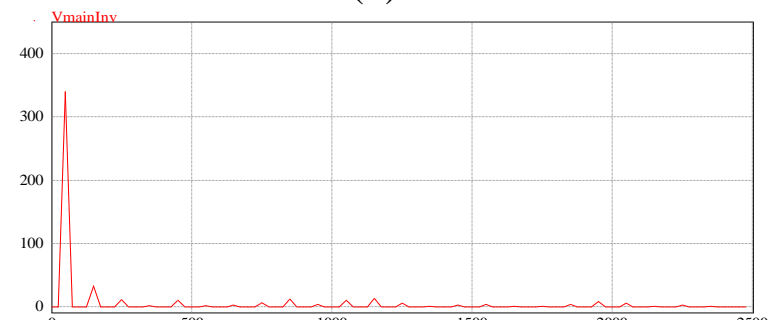

(c)

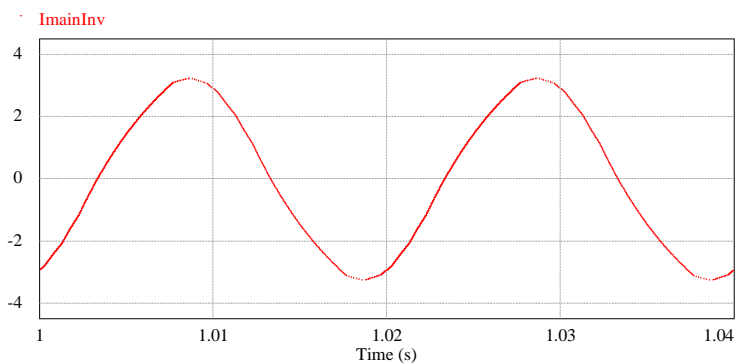

(d)

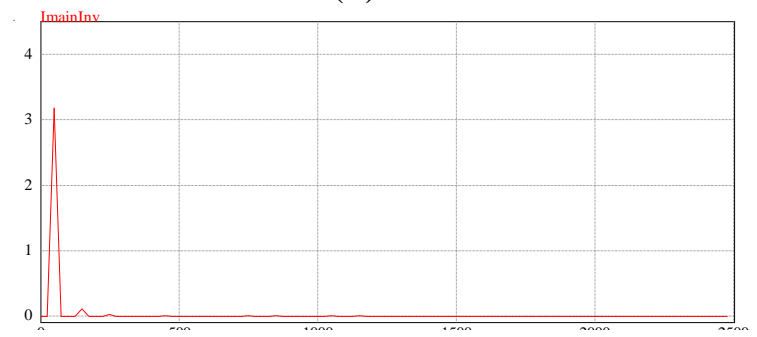

(e)

Fig. 9: (a) Multicarrier-based PWM signals at $m_{a}=1.25$, (b) the output voltage waveform, (c) voltage harmonic spectrum, the output current waveform, and (e) current harmonic spectrum.

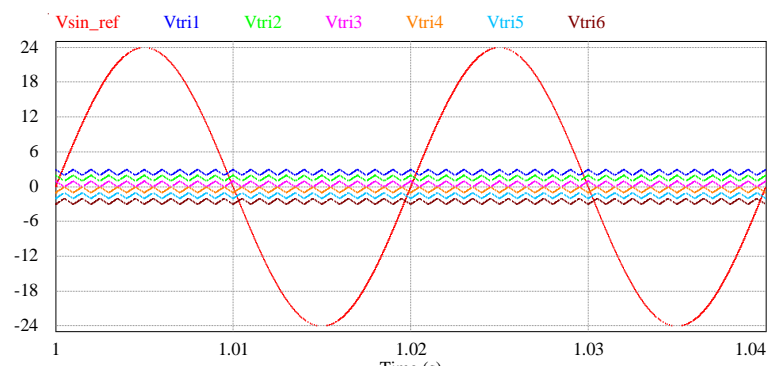

(a)

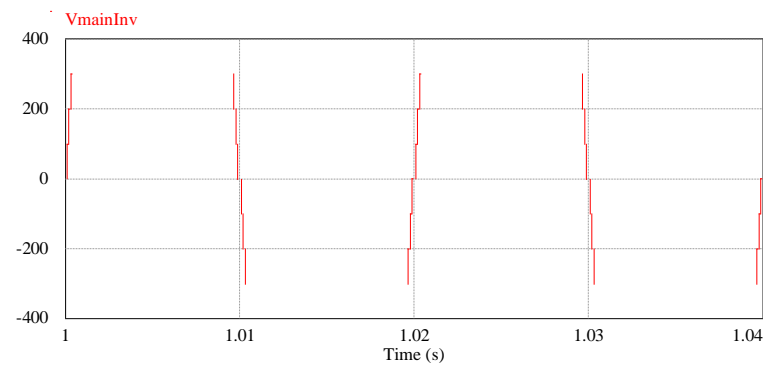

(b)

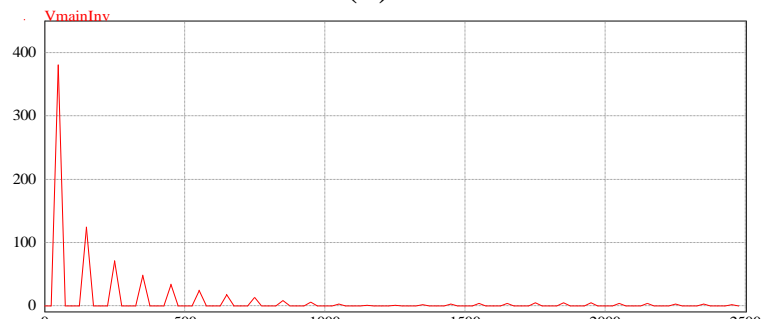

(c)

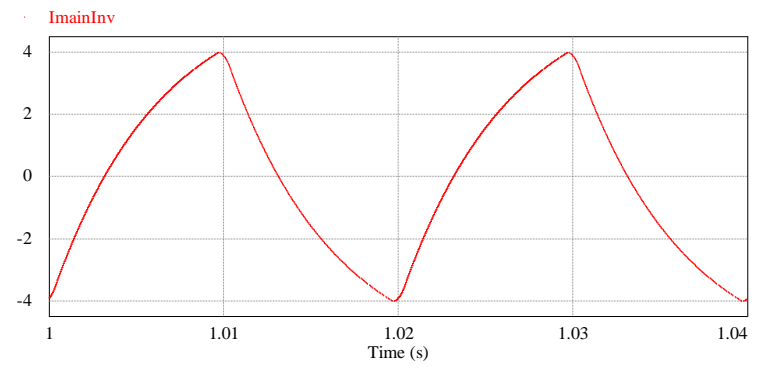

(d)

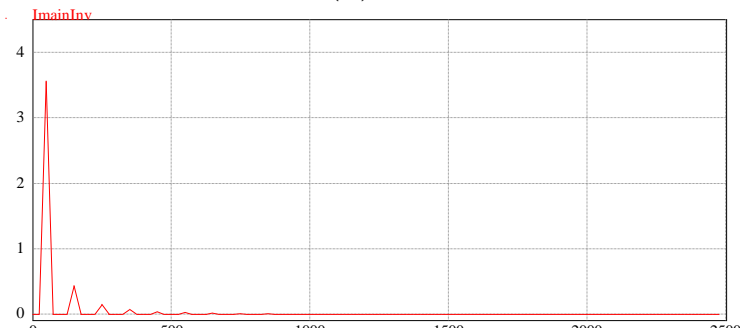

(e)

Fig. 10: (a) Multicarrier-based PWM signals at $m_{a}=3.55$, (b) the output voltage waveform, (c) voltage harmonic spectrum, the output current waveform, and (e) current harmonic spectrum. 
The simulation results of carrier-based PWM strategy operation, output voltage waveforms and their harmonic spectrums, and output current waveforms and their harmonic spectrums are given in Fig. 5, Fig. 6, Fig. 7, Fig. 8, Fig. 9, and Fig. 10. The output waveforms of Fig. 5, Fig. 6, Fig. 7, and Fig. 8 are obtained over the linearmodulation region; however, Fig. 9 and Fig. 10 results are for a modulation index in the over-modulation region. Moreover, all results show a modulation index-reliant behaviour. For instance, Fig. 5 shows results of 3-level output voltage over a range of $0<m_{a}<0.33$ while modulation reliance results over a range of $0.33<m_{a}<0.66$ are given in Fig. 6. A 7-level output voltage for $m_{a}>0.66$ is shown in Fig. 7. The results thus have shown modulation indexes as a function of featured inverters' levels.

It can be noted that sub-modules are always working normally even if the modulation index is varied over a wide range. Experimentally, this may cause imbalance switching-heat sharing that may lead to inflicting damages on the MMC's circuit.

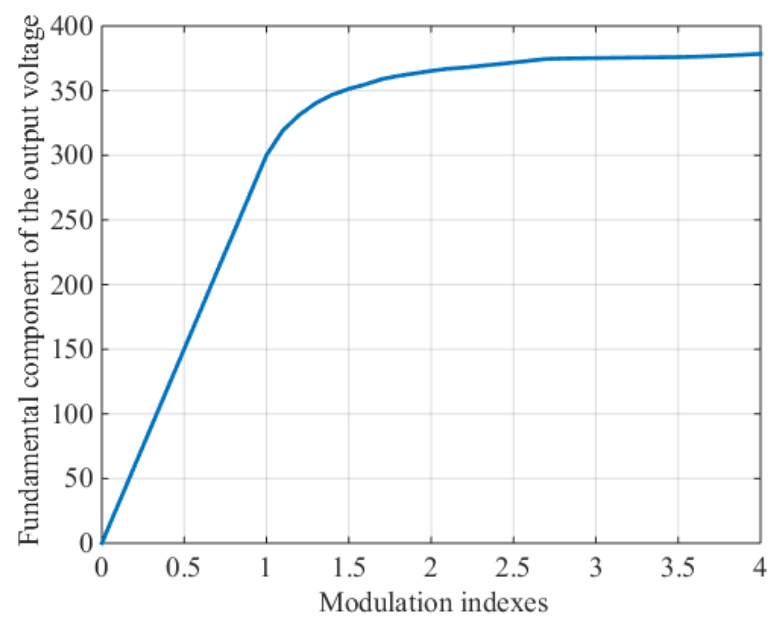

(a)

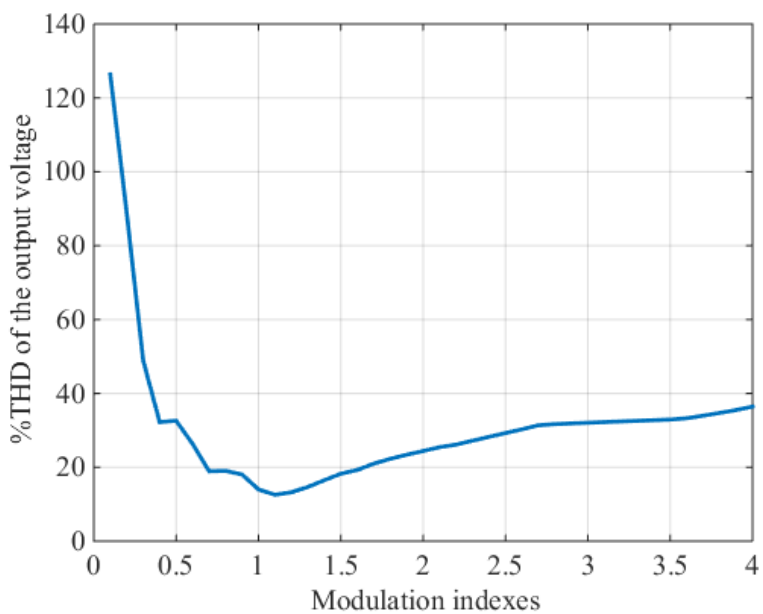

(b)

Fig. 11: (a) Fundamental component and (b) \% THD of the output voltage.

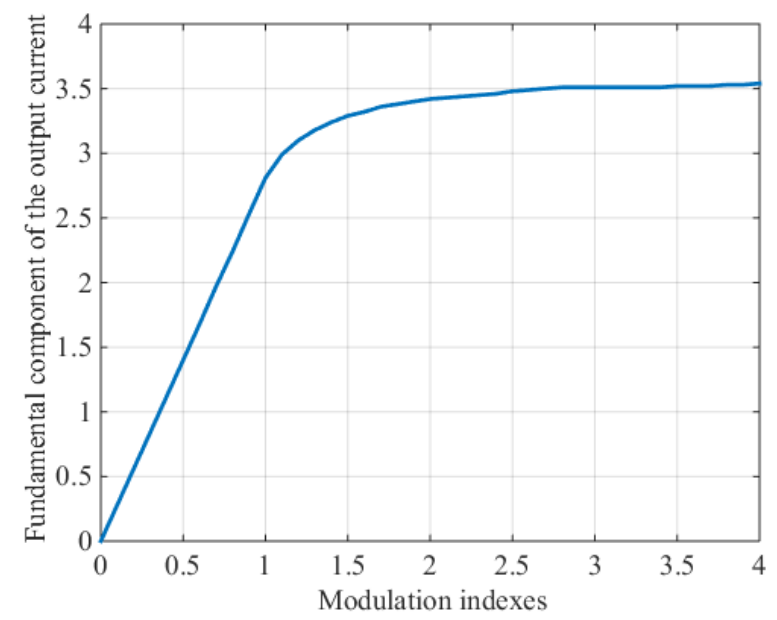

(a)

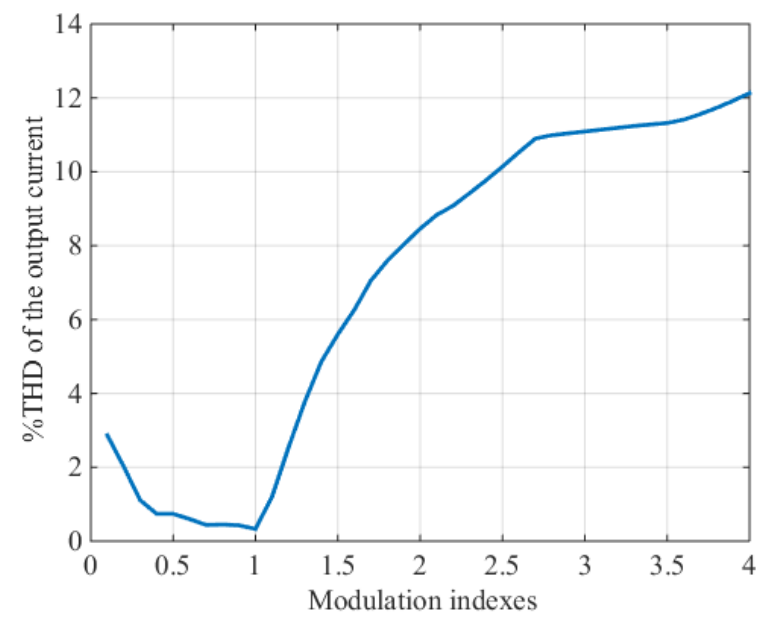

(b)

Fig. 12: (a) Fundamental component and (b) \% THD of the output current. 
The plot of the wide-range modulation index versus the fundamental component of the output voltage $\left(V_{f}\right)$, and the output current $\left(I_{f}\right)$ are illustrated in Fig. 11(a) and Fig. 12(a), respectively. Consequently, $V_{f}$ and $I_{f}$ linearly increase as $m_{a}$ is varied over the linear-modulation region until it increases, even if modulation, $m_{a}$, continues into the over-modulation region, though non-linear with a slightly reducing slope.

Figure 11(b) and Fig. 12(b) show the wide-range modulation index versus the total harmonic distortion of the output voltage (THDv) and the output current (THDi) respectively. The lowest THDv is $12.55 \%$ for a modulation index of $m_{a}=1.1$ and THDi is $0.33 \%$ for a modulation index of $m_{a}=1$. Besides, THDi is below $3 \%$ while the MMC is operated under the linear-modulation region, but it dramatically grows when $m_{a}$ increases beyond into the over-modulation region and it rises up over 5\% while $m_{a}$ is more than 1.44 .

\section{CONCLUSIONS}

This paper has presented simulation results of Multi-level Inverters made from HalfBridge Converters (HBCs) with a modulation index, $m_{a}$, ranging in values from 0 to 4 . The carrier-based PWM strategy for generating a stepped waveform is implemented using single-phase half-bridge modular multilevel converter topology. The fundamental component and the total harmonic distortion of the output voltage are presented as results. The regions of the wide range modulation variation are identified as $0-0.33,0.33-0.66$, and above 0.66 . The linear-modulation region shows linearity for the fundamental frequency component and low THDi. That means that the larger modulation indexes give larger magnitude of the fundamental frequency component. However, the linearity is lost in the case of over-modulation, that is, for a modulation index of more than 1.0, with regards to changes in fundamental component but quite high THDi. Hence, THDv (THD=12.55\%) and THDi (THDi $=0.33 \%$ ) show the lowest THD simulation results. The minimum THD values for current and voltage both appear at the boundary (modulation index of 1.0) of linear and nonlinear regions, featuring the effect of modulation index more clearly.

\section{REFERENCES}

[1] Blaabjerg F, Yang Y, Ma K, Wang X. (2015) Power electronics - the key technology for renewable energy system integration. In Proceedings of International Conference on Renewable Energy Research and Applications: 22 November 2015; pp 1618-1626.

[2] Choi UM, Lee KB, Blaabjerg F. (2012) Power electronics for renewable energy systems: Wind turbine and photovoltaic systems. In Proceedings of International Conference on Renewable Energy Research and Applications: 11 November 2012; pp 1-8.

[3] Liang X. (2017) Emerging power quality challenges due to integration of renewable energy sources. IEEE Transactions on Industry Applications, 53(2):855-866.

[4] Karimov KS, Abid M, Al-Grafi MW, Islomov SI, Karimova NH. (2013) The economics of micro hydro power plants. IIUM Engineering Journal, 14(2):173-181.

[5] Kjaer SB, Pedersen JK, Blaabjerg F. (2005) A review of single-phase grid-connected inverters for photovoltaic modules. IEEE transactions on industry applications, 41(5):1292-1306.

[6] Shi Y, Li R, Xue Y, Li H. (2016) High-frequency-link-based grid-tied PV system with small DC-link capacitor and low-frequency ripple-free maximum power point tracking. IEEE Transaction Power Electronics, 31(1):328-339. 
[7] Alajmi BN, Ahmed KH, Adam GP, Finney SJ, Williams BW. (2011) Modular multilevel inverter with maximum power point tracking for grid connected photovoltaic application. In Proceedings of 2011 IEEE International Symposium on Industrial Electronics: 27 June 2011; pp 2057-2062.

[8] Koutroulis E, Blaabjerg F. (2011) Design optimization of grid-connected PV inverters. In Proceedings of Twenty-Sixth Annual IEEE Applied Power Electronics Conference and Exposition: 6 March 2011; pp 691-698.

[9] Mahzarnia M, Sheikholeslami A, Adabi J. (2013) A voltage stabilizer for a microgrid system with two types of distributed generation resources. IIUM Engineering Journal, 14(2):191-205.

[10] Tohtayong M, Khan S, Yusoff SH, Yaacob M, Ahmed MM, Motakabber SM, Aboadla EH. (2016) Stepped waveform generation for multilevel inverter topology applications. In Proceedings of International Conference on Computer and Communications Engineering: 26 July 2016; pp 219-224.

[11] Samadaei E, Gholamian SA, Sheikholeslami A, Adabi J. (2016) Cascade topologies for the asymmetric multilevel inverter by new module to achieve maximum number of levels. IIUM Engineering Journal, 17(2):83-93.

[12] Babaei E, Laali S, Bayat Z. (2015) A single-phase cascaded multilevel inverter based on a new basic unit with reduced number of power switches. IEEE Transactions on Industrial Electronics, 62(2):922-929.

[13] Masaoud A, Ping HW, Mekhilef S, Taallah AS. (2014) New three-phase multilevel inverter with reduced number of power electronic components. IEEE Transactions on Power Electronics, 29(11):6018-6029.

[14] Buccella C, Cecati C, Cimoroni MG, Razi K. (2014) Analytical method for pattern generation in five-level cascaded $\mathrm{H}$-bridge inverter using selective harmonic elimination. IEEE Transactions on Industrial Electronics, 61(11):5811-5819.

[15] Perez MA, Bernet S, Rodriguez J, Kouro S, Lizana R. (2014) Circuit topologies, modelling, control schemes and applications of modular multilevel converters. IEEE Transactions on Power Electronics, 30(1):4-17.

[16] Edpuganti A, Rathore AK. (2015) Optimal low-switching frequency pulse width modulation of medium voltage seven-level cascade-5/3H inverter. IEEE Transactions on Power Electronics, 30(1):496-503.

[17] Zabaleta M, Burguete E, Madariaga D, Zubimendi I, Zubiaga M, Larrazabal I. (2016) LCL grid filter design of a multimegawatt medium-voltage converter for offshore wind turbine using SHEPWM modulation. IEEE Transactions on Power Electronics, 31(3):1993-2001.

[18] Varghese LJ, KeziSelvaVijila C, Raglend IJ. (2016) A survey of modulation techniques for a series connected voltage source inverters. International Journal of Advanced Engineering Technology, 7(2):571-581. 